\title{
Coordinating morphology with behavior during development: an integrative approach from a fly perspective
}

\section{Maria João A. Carvalho* and Christen K. Mirth*}

Development, Evolution and the Environment Laboratory, Instituto Gulbenkian de Ciência, Fundação Calouste Gulbenkian, Oeiras, Portugal

Edited by:

Peter Schausberger, University of Natural Resources and Life

Sciences, Austria

Reviewed by:

Emilie Snell-Rood, University of

Minnesota, USA

Claude Desplan, New York

University, USA

Roshan Kumar Vijendravarma,

University of Lausanne, Switzerland

*Correspondence:

Maria João A. Carvalho and Christen

K. Mirth, Development, Evolution and the Environment Laboratory,

Instituto Gulbenkian de Ciência,

Fundação Calouste Gulbenkian,

2780-156 Oeiras, Portugal

e-mail:mcarvalho@

igc.gulbenkian.pt;

christen@igc.gulbenkian.pt
Animals in the wild live in highly variable and unpredictable environments. This variation in their habitat induces animals, at all stages of their development, to make decisions about what to eat, where to live, and with whom to associate. Additionally, animals like insects show dramatic restructuring of their morphology across life stages, which is accompanied by alterations in their behavior to match stage-specific functions. Finally, in a process called developmental plasticity, environmental conditions feed back onto developmental mechanisms producing animals with stage-specific variation in both morphological and behavioral traits. In this review, we use examples from insects to explore the idea that animals are integrated units where stage-specific morphological and neurological traits develop together to increase individual fitness within their natural environments. We hypothesize that the same mechanisms act to alter both morphological and behavioral traits in response to the environment in which an organism develops. For example, in insects the steroid hormone ecdysone orchestrates the restructuring of the body from larva to adult form during metamorphosis at the same time as it rebuilds the central nervous system. The remodeling of both body form and nervous system structure results in behavioral alterations that match the morphological functions of the emerging adult. We review relevant findings from the fruit fly Drosophila melanogaster, combining insights from different fields like developmental biology, neurobiology and developmental plasticity. Finally, we highlight how insights drawn from $D$. melanogaster can be used as a model in future efforts to understand how developmental processes modify behavioral responses to environmental change in a stage-specific manner in other animals.

Keywords: environmental conditions, chemosensory systems, behavioral ontogeny, metamorphosis, ecdysone, IIS/TOR signaling
Over a century's worth of research in developmental biology has revealed valuable insight into the cellular, genetic, and molecular mechanisms controlling the development of a variety of animals. These studies have uncovered processes that generate a multitude of morphological characters. In addition to their effects on morphology, developmental processes alter behavior in stage-specific manners. For many animals, juvenile stages employ different behavioral repertoires than adults due to their distinct metabolic requirements, ecological niches, and physiological functions (Winston, 1991; Desor et al., 1977; Robinson, 2002; Golub and Brown, 2003; Mennella et al., 2003, 2005). In parallel, we are developing a detailed understanding of how the interaction between environmental conditions and developmental processes generates variation in body shape, size and pattern, a phenomenon termed phenotypic plasticity (West-Eberhard, 2003; Aubin-Horth and Renn, 2009; Whitman and Ananthakrishnan, 2009). Plasticity does not only apply to morphological characters. Environmental conditions can interact with developmental processes to shape phenotypic plasticity in behavior
(West-Eberhard, 2003; Aubin-Horth and Renn, 2009; Whitman and Ananthakrishnan, 2009).

In extreme cases, environmental conditions modify developmental processes to produce two or more alternative phenotypes, a phenomenon known as polyphenism. Morphological traits are integrated with alternate behavioral strategies, thus, animals show striking morph-specific behavioral differences. For example, many species of male dung beetles show polyphenism for horn length. Males that were well fed as larvae develop into adults with disproportionately long horns relative to their body size (Emlen, 1997b). They use these horns in above ground male-male courtship battles over access to females (Emlen, 1997a). On the other hand, males that were poorly fed as larvae develop rudimentary horns (Emlen, 1997b). Small-horned males use an alternative reproductive strategy: they mimic females and dig sneaker tunnels to intercept and mate with females underground (Emlen, 1997a). This illustrates how environmental conditions encountered during development can give rise to discrete morphological characters paired with the appropriate behavioral strategies in other stages. 
In this review, we draw on examples from the insect literature, primarily from the fruit fly Drosophila melanogaster, that elucidate the molecular mechanisms underlying how behavioral responses to environmental cues are specified at different developmental stages (Figure 1A). We first outline the literature that aims to uncover how variation in environmental conditions generates variation in behavioral responses in $D$. melanogaster (Figure 1B). Then, after briefly introducing the developmental mechanisms that regulate stage transitions in insects, we delve into how development reprograms behavior to generate stagespecific behavioral variation (Figure 1B). Finally, we combine these findings to understand how environmentally-induced plasticity in developmental mechanisms ensures that morphological and neuronal traits match (Figure 1B). We hypothesize that the same developmental processes that alter morphological characters simultaneously alter the activity and connectivity of the nervous system to induce appropriate alterations in behavior. With this, we aim to provide a novel synthesis of the interactions between the environment, development, and behavior (Figure 1A).

\section{ENVIRONMENTAL MODULATION OF VARIATION IN BEHAVIOR}

The neuroanatomical basis for learning and behavior is a broad field of study and has been covered in myriad reviews (Menzel and Muller, 1996; Johnson, 2001; Roman and Davis, 2001; Gerber and Stocker, 2007; Gerber et al., 2009). Here, instead of exhaustively reviewing the literature of the neural circuitry underlying these processes, we will outline the overall structure of information flow through the nervous system and then focus on how selected examples of how environmental conditions contribute to variation in behavioral output at a given life stage.

To convert information from the environment to the appropriate behavioral responses, animals use a combination of somatosensory, visual, auditory, chemical, and mechanical inputs to acquire information about their surroundings (Huston and Jayaraman, 2011). This information is processed and interpreted in the brain and useful motor outputs are generated which allow animals to react to their environment, to escape predators, to find food, to choose a mate or to perform a variety of other behaviors (Figure 2). Furthermore, to produce useful behavioral outputs in particular contexts, the sensorimotor transformations have to be flexible enough not only to accommodate multisensorial information from a dynamic environment but also to be sensitive to other variables such as posture, active sampling strategies, behavioral state, internal state, origin of the stimuli (internal or external) and experience (Huston and Jayaraman, 2011).

The sensory cells bearing the receptors for olfactory, gustatory and somatosensory cues have been described in both larval and adult D. melanogaster. Odorants and tastants are sensed by olfactory and gustatory receptors distributed across external sensory organs, like the terminal, ventral and dorsal organs in larvae and the chemosensory bristles in the antennae, palps, tarsi, wings and genital structures of the adult (Scott, 2005; Vosshall and Stocker, 2007; Benton, 2008). Additionally, the organization of these neuronal circuits is maintained throughout development.
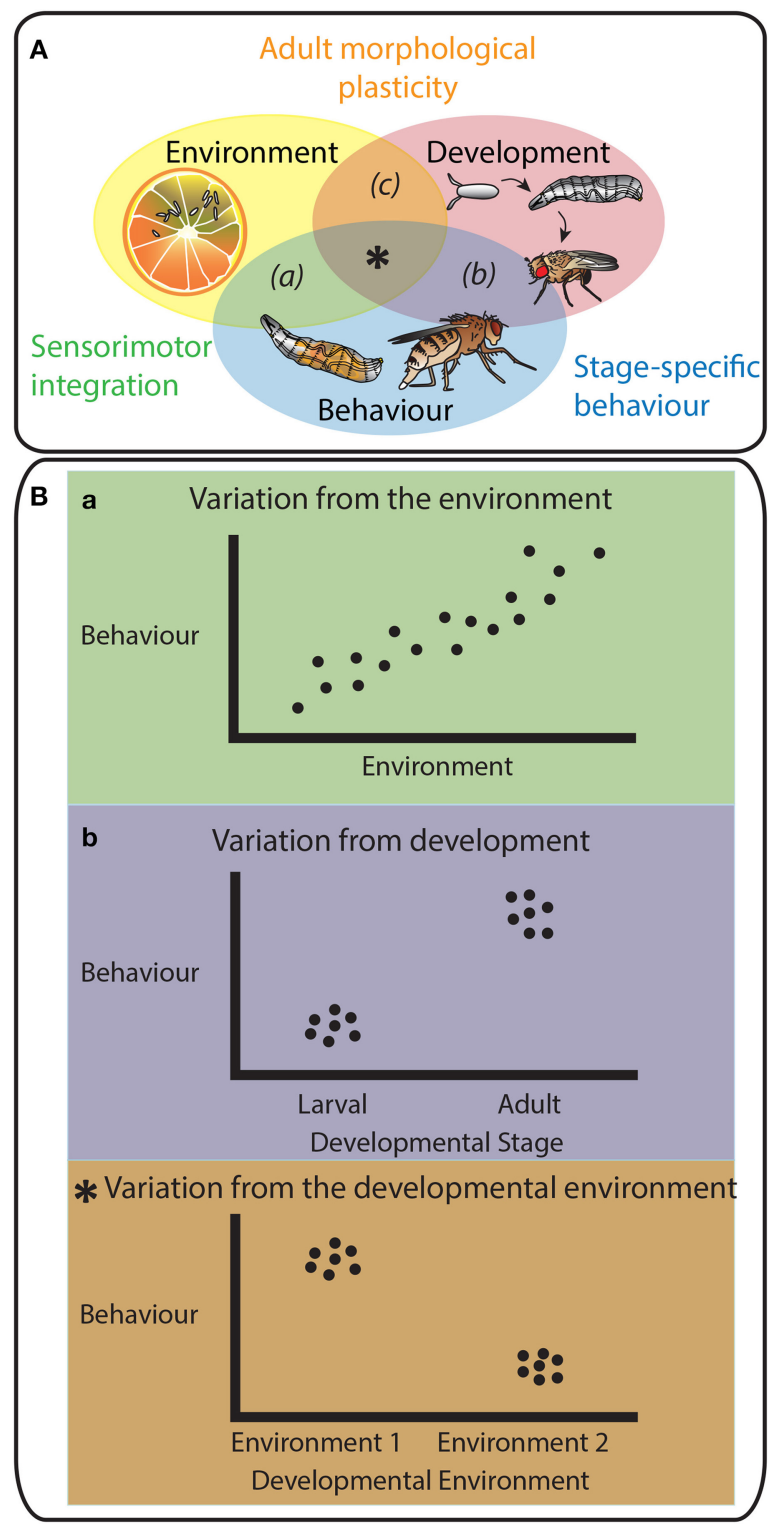

FIGURE 1 | The triad Environment-Development-Behavior. (A) Schematic representation emphasizing the interactions between three factors: Environment, Development and Behavior. These interactions are essential in the determination of an animal's survival and fitness in an ecological context. Animals produce motor outputs in response to chemosensory cues from their environment (a) via sensorimotor integration. Behavior is partially hard-wired with developmental programs (b) as the neuronal connections are set throughout development resulting in stage-specific behaviors. Animal development is plastic to environmental conditions as the interaction between the environment and development (c) determines adult morphological phenotypes. This review raises the possibility that the mechanisms of morphological plasticity also modulate the activity and connectivity of neuronal circuits. Environmental variations would impact both morphological and behavioral traits through common molecular players. This would ensure animals use the appropriate behavioral repertoire for their morphology (central intersection,*). (B) shows schematic representations of the behavioral reaction norms toward different factors, environment $(a)$ and development $(b)$ alone, and to their intersection $(*)$. (a), (b), and $\left({ }^{*}\right)$ and respective colors match the codes and explanations used in panel $\mathbf{A}$. 


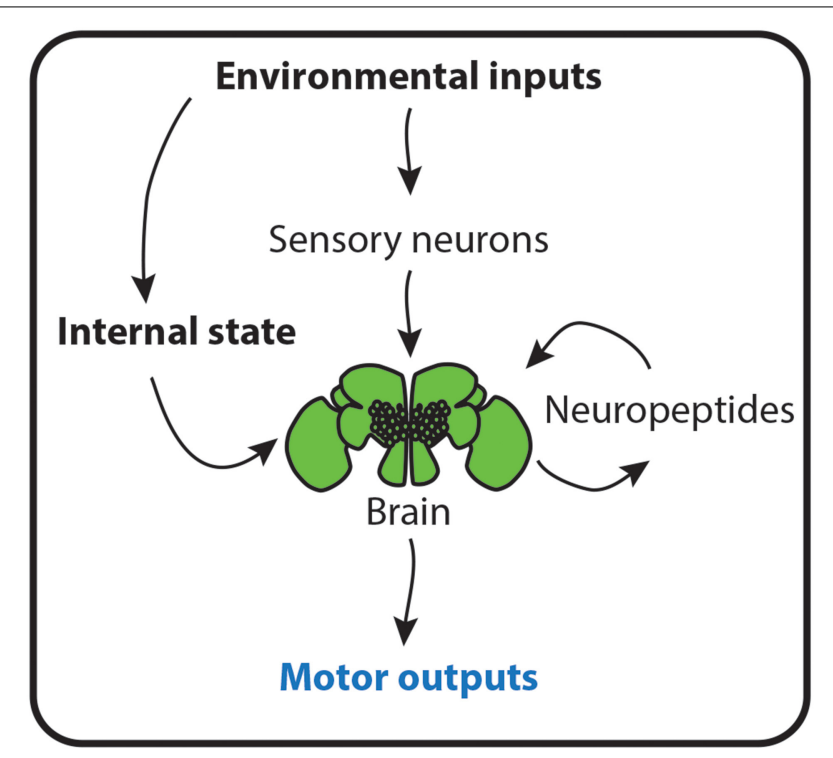

FIGURE 2 | Environment determines behavior. A schematic representation of how environmental cues instruct animals about their contexts to produce useful behaviors. Inputs from the environment activate peripheral sensory neurons that innervate the brain. Here, the sensory information is interpreted and processed into motor outputs. The environment also changes the physiological state of animals. This environmental-dependent internal state is either sensed by the brain and directly converted into behaviors, or leads to the production of neuropeptides, which mold the interpretation of sensory cues from the environment and thus, animal behavior.

Although D. melanogaster larvae and adults have completely different lifestyles and body morphologies, the basic architecture of the olfactory circuit, including receptor gene expression and neuronal circuitry, is maintained and the gustatory circuit is partially conserved between the larva and adult fly (Gerber and Stocker, 2007).

In addition to the chemosensory neuronal circuits, there are other circuits that allow organisms to react to mechanical stimuli, the position of their body parts in space, thermal conditions, and others cues. D. melanogaster larvae show four classes of dendritic arborization $(d a)$ sensory neurons that tile the epidermal segments to generate a complex web of non-overlapping, nonredundant sensory fields whose somas and axons are wrapped by glia in different regions of the brain (Bodmer and Jan, 1987; Grueber et al., 2002, 2007). Several studies have recently identified these peripheral neurons as the responsible for translating environmental cues into nocifensive behaviors and taxis (Sawin et al., 1994; Kaneko et al., 1997; Renn et al., 1999; Malpel et al., 2002; Liu et al., 2003; Tracey et al., 2003; Mazzoni et al., 2005; Rosenzweig et al., 2005; Dhaka et al., 2006; Hamada et al., 2008; Kang et al., 2010, 2012; Xiang et al., 2010; Zhong et al., 2010; Kane et al., 2013; Ohyama et al., 2013).

In response to noxious heat stimuli, larvae employ two nocifensive behaviors, a rolling motor behavior toward the side of the body that was stimulated (Im and Galko, 2012) and an escape crawl typically performed after rolling where the larvae alter their crawling speed (Ohyama et al., 2013). The da class IV neurons are both necessary and sufficient for triggering these behaviors (Im and Galko, 2012), and receptors for nociception expressed in these neurons have been identified in larvae (Tracey et al., 2003; Kang et al., 2010, 2012; Zhong et al., 2010). The receptor painless was shown to be required for both thermal and mechanical nociception, but not for sensing light touch (Tracey et al., 2003). Additionally, this nociceptive behavior is ecologically relevant. Class IV da neurons are activated when the larval cuticle is penetrated by parasitoid wasps (Robertson et al., 2013). The rolling output allows the larvae to release themselves from their attackers (Hwang et al., 2007).

Although rolling and escape crawl behaviors are stereotyped responses to noxious stimuli, the frequency at which larvae perform these behaviors depends on environmental conditions. Larvae roll at higher frequencies in response to noxious heat when assayed under conditions of high ambient heat $\left(32^{\circ} \mathrm{C}\right)$ than when they are assayed under standard ambient heat $\left(25^{\circ} \mathrm{C}\right)$ (Ohyama et al., 2013). Furthermore, when Class IV da neurons are activated, using optogenetic techniques, in larvae crawling on an agar surface, these larvae show an increase in the frequency of escape crawl behavior. If these same neurons are activated in larvae immersed in water, they show increased rolling frequencies (Ohyama et al., 2013). This illustrates how variation in environmental conditions generates variation in behavioral output.

Environmental conditions induce variation in behavioral outputs, at least in principle, by either acting directly to modify the sensitivity of neurons that detect environmental or physiological stimuli (Ohyama et al., 2013), or indirectly by altering the synthesis and secretion of neuromodulators like biogenic amines and neuropeptides, thereby altering neuronal activity and connectivity (Nassel, 2002). In the locust, Locusta migratoria, the concentration of amino acids in the haemolymph, or insect blood, directly affects the responsiveness of gustatory receptors in the maxilla; low amino acid levels increase sensitivity of these neurons to amino acid stimulation (Simpson and Simpson, 1992). In D. melanogaster adults, gustatory receptor 43a-expressing brain neurons function as nutrient sensors for haemolymph fructose and alter feeding rates in accordance with hunger state (Miyamoto et al., 2012). Furthermore, the amino acid sensor GCN2 acts upstream of GABA signaling in dopaminergic neurons to alter feeding rates on diets deficient in essential amino acids in D. melanogaster larvae (Bjordal et al., 2014).

In addition to direct sensing of nutrients, neuronal circuits respond to an array of neuropeptides. Chemical signals in the environment affect the production of neuropeptides to control feeding rates according to the metabolic state of the organism. For example, in response to nutritional conditions, post-ingestive modulators produced by the animal's endocrine system couple internal state with altered physiology of the neuronal circuits (Pool and Scott, 2014). D. melanogaster feeding behavior is known to be regulated by neuropeptides such as insulin-like peptides (ILPs), Neuropeptide F (NPF), small Neuropeptide F (sNPF), and Hugin (Nassel and Winther, 2010).

NPF is the vertebrate homolog of the neuropeptide Y (NPY) in D. melanogaster (Brown et al., 1999). NPF expression levels are regulated throughout development. During larval feeding 
stages, $n p f$ is highly expressed. In contrast, $n p f$ expression levels are downregulated in non-feeding stages of $D$. melanogaster, from the onset of wandering to adult emergence after metamorphosis. Overexpressing $n p f$ prolongs the larval feeding period and delays wandering and metamorphosis. In agreement with the ontogeny of the NPF levels, this neuropeptide responds to gustatory stimulation. In the presence of sugars, the levels of NPF increase (Nassel and Winther, 2010; Nassel and Wegener, 2011).

The insulin/insulin-like growth factor signaling (IIS) pathway controls many nutrition-related responses, including increased feeding rates due to starvation (Wu et al., 2005a). In response to nutrition, D. melanogaster produces and secretes ILPs from several organs (Koyama et al., 2013), including the insulin producing cells (IPCs) in the brain (Rulifson et al., 2002; Broughton et al., 2005). ILPs act in an endocrine manner by binding to the cellsurface insulin receptor (InR) and triggering the IIS cascade. IIS regulates feeding rates, in part, by regulating NPF production. Well-fed larvae reduce their feeding rates when presented with non-attractive cold or bitter food (Wu et al., 2005b; Lingo et al., 2007). However, starving larvae decreases ILP secretion, causing an increase in the production of NPF. In response to increased $\mathrm{NPF}$, larvae increase their feeding rate on bitter or cold food (Wu et al., 2005a,b; Gu et al., 2009; Lingo et al., 2007).

Small NPFs (sNPF), although structurally related with NPF, are encoded by different genes. Several studies have shown that these neuropeptides are involved in the modulation of feeding and growth through the regulation, via extracellular regulated kinase (ERK), of ILP production (Lee et al., 2004, 2008b, 2009). A local signal by sNPF and a global metabolic cue by IIS pathway are integrated at specific odorant receptor neurons (ORNs) to modulate olfactory sensitivity. Expression of sNPF and its receptor (sNPFR1) in Or42b neurons is necessary for starvationinduced food-search behavior. In contrast, under fed states, high levels of ILPs downregulate sNPFR expression in Or42b neurons, decreasing olfactory sensitivity (Root et al., 2011).

Finally, the hugin gene encodes a neuropeptide shown to regulate behavioral responses to chemical cues. This gene is expressed in the subesophageal ganglion of the brain in D. melanogaster. Although hugin produces two neuropeptides, Hugin-PK, but not Hugin, has been biochemically identified in the nervous tissues (Nassel and Winther, 2010). Depending on the nutritional status of the fly, Hugin-PK modulates the processing of gustatory information and changes feeding behavior (Melcher and Pankratz, 2005). hugin neurons, by terminating in different organs, coordinate various aspects of feeding. The release of Hugin-PK controls growth and metabolism by acting on a composite gland that produces developmental hormones, the ring gland, modulates feeding by acting in the pharynx muscles, and transmits gustatory signals to the protocerebrum (Bader et al., 2007; Melcher et al., 2007).

\section{SUMMARY}

In dynamic and often unpredictably variable environments, an animal's ability to sense external stimuli and to react by producing useful behavioral outputs is crucial for its survival, optimization of its life strategies and reproductive rates (Figure 2). We are beginning to understand the mechanisms that underlie the ability of an animal to modify its behavioral output in response to its environmental context. These include direct alterations in the sensitivity of sensory neurons in response to environmental or physiological conditions and alterations in circuit physiology due to changes in environmentally-sensitive neuropeptide production. These processes allow environmental variation to induce variation in behavior within a stage, and may underlie stage-specific or developmentally plastic alterations in behavior between stages.

\section{INSECT DEVELOPMENTAL ENDOCRINOLOGY: A BRIEF OVERVIEW}

To form an adult, all living animals go through a developmental period that starts with the fertilized egg and ends at reproductive maturity. This period includes a series of processes that lead to growth and differentiation of tissues. During their development, insects are faced with the problem of growth under a rigid exoskeleton. To overcome this problem, they form a new exoskeleton below the old one, shedding the latter when the new one is formed. Then, the new exoskeleton is enlarged and hardened to accommodate a new wave of body and organ growth. This process of molting occurs at defined times during development and depends on pulses of several different hormones. The timing and quantity of developmental hormone titres, in turn, depend on environmental conditions. These pulses, together with growth signaling pathways, such as the IIS, coordinate body and organ size with developmental progression (Figure 3).

Several environmental variables regulate hormonal pulses throughout insect development (Emlen and Nijhout, 1999; Caldwell et al., 2005; Colombani et al., 2005a; Mirth et al., 2005; Layalle et al., 2008; Gu et al., 2009; Walkiewicz and Stern, 2009; Walsh and Smith, 2011). For instance, in response to

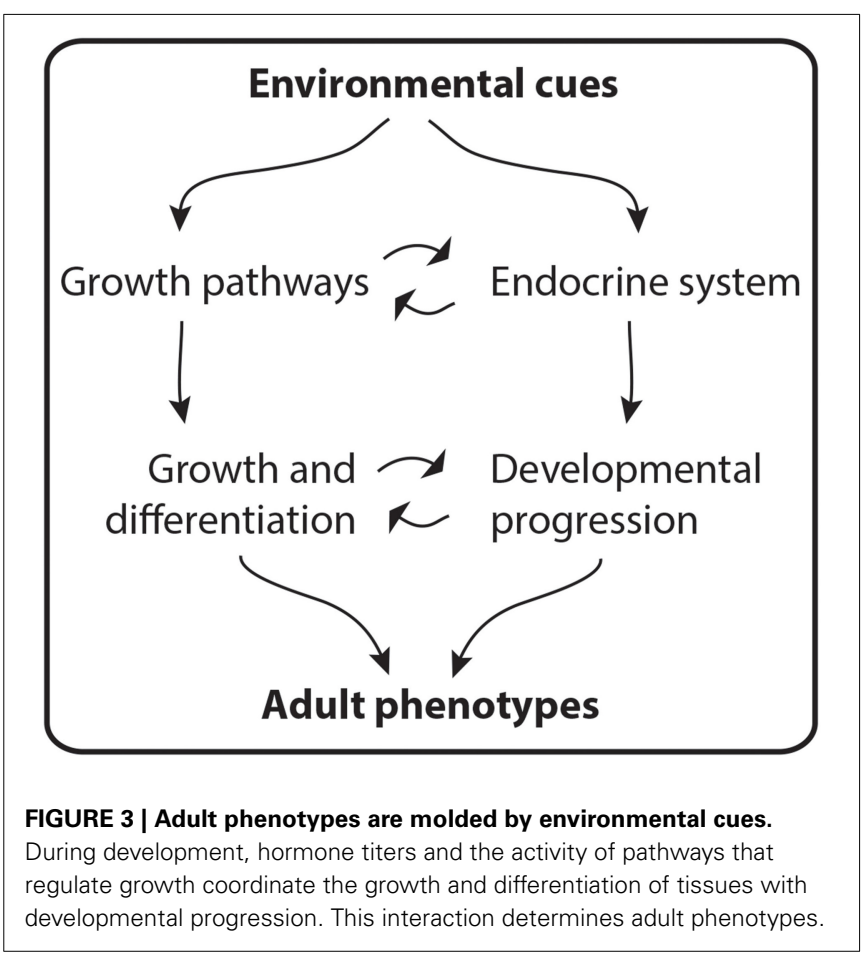


photoperiod the neuropeptide prothoracicotropic hormone is released (Truman and Riddiford, 1974; Mirth et al., 2005). The prothoracicotropic hormone activates the Torso/ERK pathway (Rewitz et al., 2009) in prothoracic glands to trigger the production and release of ecdysone, the precursor of the active steroid molting hormone 20-hydroxyecdysone (Gilbert et al., 2002; McBrayer et al., 2007). The increased level of 20-hydroxyecdysone provides a systemic signal that induces larval/nymphal and metamorphic molts (Koyama et al., 2013).

Juvenile hormone $(\mathrm{JH})$ is a sesquiterpenoid hormone produced in the corpora allata. This hormone is known as a "status quo" hormone because it prevents transitions between life stages (Riddiford, 1996). Thus, in many holometabolous insects, insects that undergo complete metamorphosis, high levels of $\mathrm{JH}$ only allow larval to larval molts. To initiate metamorphosis, JH levels have to drop (Williams, 1961).

Both ecdysone and $\mathrm{JH}$ affect cell proliferation. Ecdysone has different effects depending on its concentration; whereas moderate levels of ecdysone are necessary for cell proliferation, high levels of ecdysone prevent it (Champlin et al., 1999). JH affects cell proliferation by modulating the effects of ecdysone (Koyama et al., 2013).

\section{SUMMARY}

During development, the insect endocrine system produces a set of hormones common to most species and essential in coordinating the growth and differentiation of tissues with developmental progression. The timing and concentrations of hormone titres are sensitive to environmental cues (Figure 3). How endocrine organs sense particular external cues and how different hormonal titres impinge on developmental programs to modify developmentally plastic traits is an active area of research.

\section{DEVELOPMENTAL REPROGRAMMING OF THE NERVOUS SYSTEM TO GENERATE STAGE-SPECIFIC BEHAVIOR}

The type of behavioral outputs employed in response to an external cue depends on the animal's developmental stage. Arguably, holometabolous insects exhibit the most dramatic developmental rewiring of their nervous systems (Figure 4A). Approximately 10,000 larval neurons arise from neuroblasts during embryogenesis. During the pupal stage, these larval neurons will adopt one of two fates: (1) they will undergo programmed cell death and their function will be replaced by adult-specific neurons or (2) they will become remodeled to make new connections with adult-specific neurons (Truman, 1990). Adult-specific neurons arise from retained embryonic neuroblasts that undergo a second, more prolonged wave of neurogenesis during the larval period (Booker and Truman, 1987; Truman and Bate, 1988; Prokop and Technau, 1991; Truman et al., 2004). Neurons derived from this second wave develop simplified, undifferentiated projections in the larval stages, and only undergo differentiation to make their final connections during the pupal phase (Booker and Truman, 1987; Truman and Bate, 1988; Truman et al., 2004). Neurogenesis during larval stages results in an approximately 10-fold expansion in neuron number. In the thoracic segments, this expansion accommodates the new sensory and motor demands of the legs and wings (Levine, 1984). Further, expansion of the learning centers in the central brain, including the mushroom bodies and central complex neurons, are reflected in the expanded behavioral repertoire of the adult (Technau and Heisenberg, 1982).

The nervous system of insects is not the only tissue that remodels dramatically. The musculature used for crawling in dipteran and lepidopteran larvae largely degenerates, and is replaced by adult muscles for flight and walking (Perez, 1910; Hufnagel, 1918; Levine and Truman, 1985; Weeks and Truman, 1985). This poses

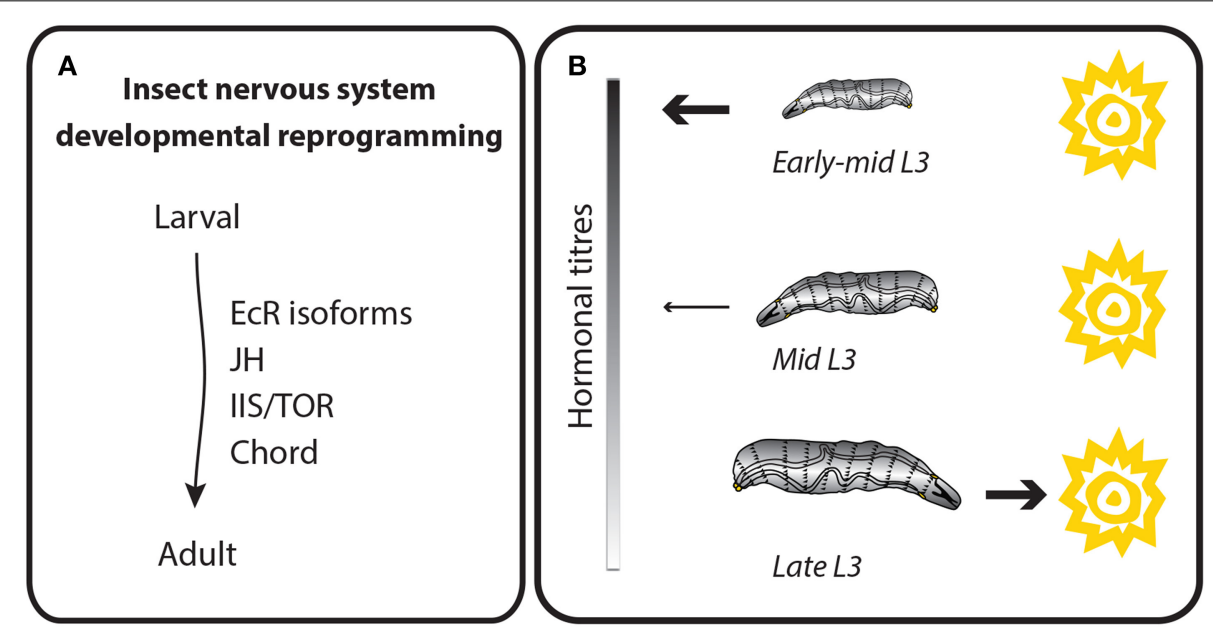

FIGURE 4 | Behavioral outputs depend on the developmental stage. Behavioral outputs are reprogrammed throughout development. Thus, each developmental stage is hardwired with specific motor outputs in response to environmental conditions. (A) Schematic representation of the main molecular regulators of insect neuronal reprogramming during development. Hormone $(E c R$, ecdysone receptor and JH, Juvenile hormone) and growth signaling pathways (IIS/TOR = insulin/insulin-like growth factor signaling and Target of Rapamycin) are known to be important for the differentiation and remodeling of the nervous system during development. (B) Example of a stage-dependent behavior in D. melanogaster larvae. Larvae show different phototaxis depending on its developmental stage. The molecular pathway that regulates this switch is not yet known, but depends on hormonal titres occurring throughout development. 
a specific challenge for the persistent larval motor neurons that reconnect to new targets to regulate adult-specific functions. In the tobacco hornworm, Manduca sexta, many of the motor neurons associated with the muscles that innervate the abdominal body wall muscles form new targets in the adult abdomen (Levine and Truman, 1982). Once such motor neuron, MN-1, innervates dorsal external oblique muscles in larvae, but loses this target in the pupal stage to innervate a new dorsal external muscle (DE 4). MN-1 also receives input from a stretch receptor (SR3 ), which is present throughout insect life. In the larva, MN-1 receives excitatory input from the SR-3 on the same side as the target (ipsilateral), but is inhibited by the SR-3 on the opposite (contralateral) side. In contrast, in the adult, the contralateral SR-3 becomes excitatory. Because MN-1 undergoes substantial remodeling and expansion of its contralateral arbor during metamorphosis, new connections formed during the pupal stages presumably allow $\mathrm{MN}-1$ to change in response to SR-3, thereby reprogramming the behavioral outcome.

This transformation from the larval to adult nervous system is complex and relies on cues from developmental hormones for its coordination. Ecdysone induces many developmental processes during the metamorphosis of the insect nervous system. Ecdysone binds to a heterodimeric receptor formed by Ecdysone Receptor (EcR) and Ultraspiracle. EcR in D. melanogaster has three isoforms, EcR-A, EcR-B1, and EcR-B2. During metamorphosis, the nervous system predominantly expresses EcR-A and EcR-B1 (Truman et al., 1994). Most larval neurons express EcR-B1 during larval development, but switch to EcR-A during pupal development. A separate class of larval neurons expresses notably higher levels of EcR-A in pupal stages, and these cells are fated to die during metamorphosis. Adult-specific neurons express EcR-B1 when they are undergoing proliferation, and EcR-A during differentiative phases of development. Thus, the expression of particular isoforms correlates with neuronal type and developmental stage.

Although the functional significance of EcR isoform expression is still unclear, neurons clearly require signaling through EcR to remodel and differentiate during metamorphosis. Larval sensory and neurosecretory neurons in the thorax require EcRmediated signaling to prune back their larval arbors and, later, to elaborate adult-specific outgrowths (Williams and Truman, 2005; Brown et al., 2006). Similarly, adult-specific neurons require EcR signaling for the differentiation of their arbors; interfering with EcR function results in sparse, compacted arbors in a range of neuronal types (Brown and Truman, 2009). In both cases, blocking EcR signaling does not prevent differentiation completely. This suggests that other developmental cues, potentially other hormones or interactions between the cells of the nervous system, are important for initiating and driving neuronal development.

$\mathrm{JH}$ is also known to play a role in the timing of neuronal differentiation in D. melanogaster, at least in some cell types. Many of the $d a$ neurons die at the onset of metamorphosis, but some remain to carry out sensory functions in adult (Shepherd and Smith, 1996; Williams and Shepherd, 1999). Like the MN-1 motor neuron, da neurons initially prune back their larval arbors while larval tissue degenerates in the pupal stages. These neurons later undergo a program of expansion to produce the adult arbor (Williams and Truman, 2004). Ectopic application of a JH mimic, pyriproxifen, prolongs the dendrite pruning stages and represses the expansion phase in persistent $d a$ neurons (Williams and Truman, 2004). Conversely, lack of JH promotes premature outgrowth in some neurons such as the R7 photoreceptors in the developing visual system (Riddiford et al., 2010). Thus, both hormones important for controlling developmental transitions, $\mathrm{JH}$ and ecdysone, play a role in the transition between larval and adult nervous systems.

Remodeling the nervous system between life stages occurs to accommodate stage-specific behavioral repertoires. D. melanogaster larvae spend most of their time feeding by crawling on and digging into food. In the late third instar, larvae cease feeding and leave the food to find a suitable place for pupariation, a behavior referred to as wandering (Sokolowski et al., 1984). The transition from foraging to wandering is determined by a peak of ecdysone that occurs before the wandering phase and approximately $30 \mathrm{~h}$ after critical weight for pupariation is attained (Mirth and Riddiford, 2007). During the foraging phase, larvae are sensitive to odor and humidity (Grossfield, 1978). Additionally, from hatch until early-mid third instar, D. melanogaster larvae avoid light (Sawin-McCormack et al., 1995) but by mid third instar, larvae begin to show a decrease in their photonegative behavior, until just before pupation when the avoidance response of wandering larvae to light is lost (Sawin-McCormack et al., 1995) (Figure 4B).

Work over the past 20 years has generated an understanding of the genes and neurons regulating visual processing, and the endocrine regulators of this switch in light avoidance in D. melanogaster larvae (Keene and Sprecher, 2012). The prothoracicotropic hormone acts directly on two light sensors, the Bolwig's organ and the peripheral class IV $d a$ neurons, to alter behavior toward light in third instar larvae as they approach wandering (Yamanaka et al., 2013). How this sensory information is translated into alterations in motor output is not yet completely understood (Sawin-McCormack et al., 1995; Gong et al., 2010). However, it is clear that the same endocrine cues that drive development of morphological traits also reshape behavior between life stages.

\section{SUMMARY}

In many animals, the activity and connectivity of the nervous system undergoes dramatic changes during development. Both hormonal and growth signaling pathways are known to be important for the differentiation and remodeling of the insect nervous system (Figure 4A). This, together with other stage-specific traits, defines the range of behaviors associated with each developmental stage. Researchers have paid considerable attention to describing the development of the nervous system, and some advances have been made regarding the development of behavior. However, the connection between the ontogeny of behavior and the changes at the level of neural circuits are still being addressed.

\section{ENVIRONMENTAL REPROGRAMMING OF DEVELOPMENT TO GENERATE MORPHOLOGICAL PLASTICITY}

Developmental processes are not completely rigid, but respond to environmental conditions (Figure 5). In the most extreme cases, variable environmental conditions lead to the formation 


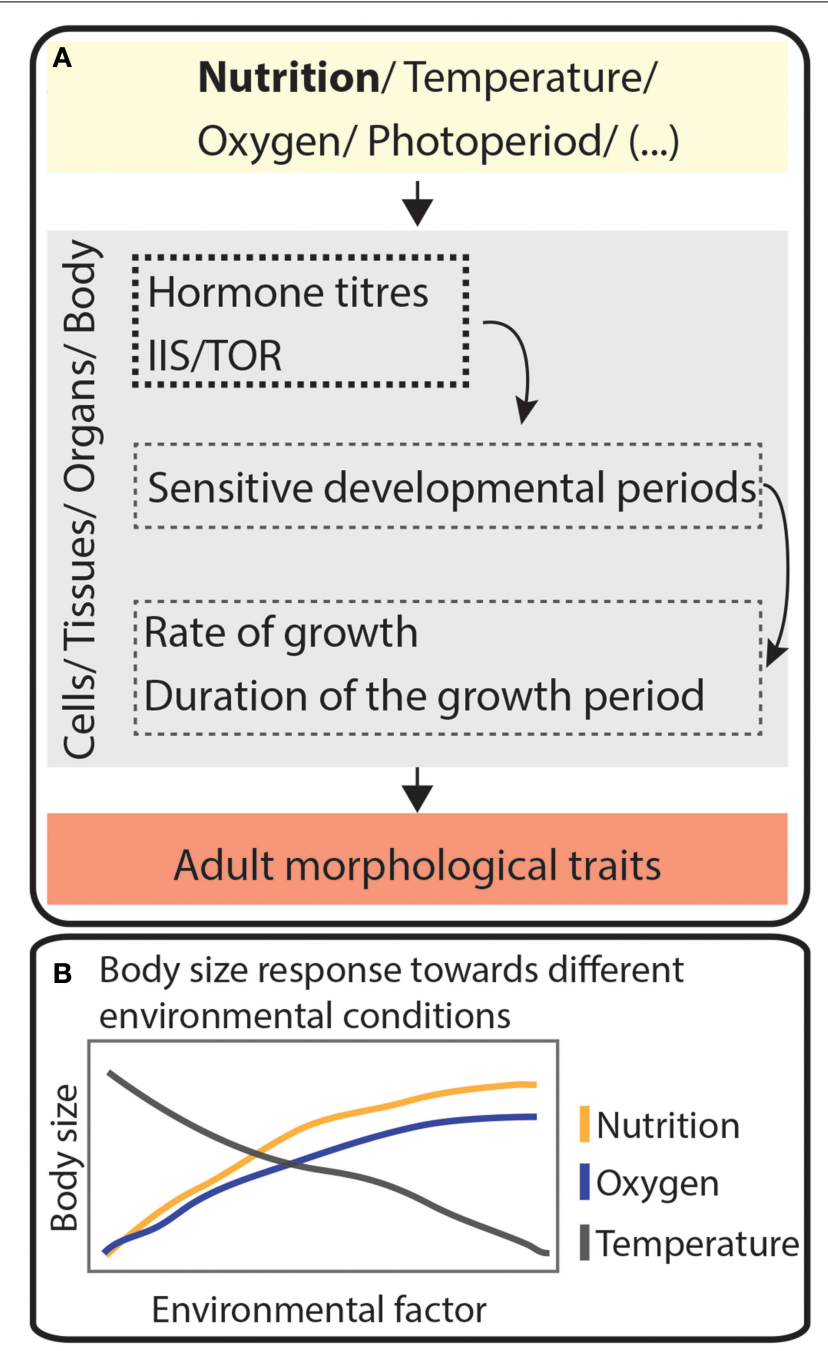

FIGURE 5 | Environmental cues mold adult plastic traits. (A) Schematic cascade showing how different environmental factors act at sensitive developmental periods of cells, tissues, organs or body to modify adult morphological traits. Hormone titers and the activity of the IIS/TOR pathway (IIS/TOR = insulin/insulin-like growth factor signaling and Target of Rapamycin) depend several environmental conditions. Together, these pathways will act on cells, tissues, organs or in the whole body to change the rate of growth, the duration of the growth period or both. This will allow the appearance of different adult phenotypes according to the environment. (B) Schematic representation of how insect body size may change in response to variation in three environmental conditions, temperature, nutrition, and oxygen levels.

of ecomorphs, organisms that show morphological traits that reveal their ecological context, showing greater similarity under the same ecological conditions regardless of their genotype.

There are many environmental variables that affect animal's developmental programs and that impact their growth and their morphology. D. melanogaster bears a number of traits whose development responds to environmental conditions, and this organism has emerged as one of the best models for understanding how nutrition regulates body size (Mirth and Shingleton, 2012).
An animal's nutritional requirements are complex, composed of specific combinations and quantities of macronutrients, vitamins, minerals, and water (Raubenheimer and Simpson, 1997; Simpson et al., 2003). In some cases, the quantity of a given food source during the juvenile stages can induce polyphenisms (Emlen, 1994). However, the balance between specific macronutrients is known to mediate developmental trade-offs between traits (Lee et al., 2008a; Sentinella et al., 2013; Cassidy et al., 2014; Cordes et al., 2014; Jaramillo et al., 2014). It remains unclear whether the same mechanisms regulate developmental responses to both food quantity and nutrient balance.

What we do know is that body size in most animals results from the regulation of two nutrition-dependent processes: (1) the rate of growth and (2) the duration of the growth period. In insects, the hard exoskeleton of the adult prevents growth, thus the length of the larval stages determine the duration of the growth period. Nutrition regulates growth rate via IIS and Target of Rapamycin (TOR) signaling pathways, signaling cascades conserved across animals. The IIS and TOR signaling pathways control the duration of the growth period by regulating the timing of hormone peaks (Grewal, 2009; Koyama et al., 2013, 2014).

As previously discussed, IIS signaling tunes developmental processes and behavioral responses to environmental conditions via nutrition-sensitive secretion of ILPs (Koyama et al., 2013). Once ILPs bind to their receptor in target tissues, they activate a phosphorylation cascade which includes PI3 kinase (PI3K) and Akt (Oldham and Hafen, 2003; Grewal, 2009; Koyama et al., 2013). PI3K/Akt signaling targets the negative growth regulator transcription factor, Forkhead Box class O (FoxO) (Junger et al., 2003; Burgering, 2008), by phosphorylating this protein causing it to be translocated from the nucleus.

TOR signaling, a second nutrition-sensitive cascade, is activated in a cell-autonomous manner either by signaling through ILP/PI3K/Akt or in response to the available extracellular nutrients, mostly amino acids and oxygen, via TOR kinase itself (De Virgilio and Loewith, 2006). There is extensive crosstalk between the insulin/PI3K/Akt and TOR signaling. Therefore they are often considered to be branches of the same pathway, the IIS/TOR signaling pathway. In a feedback loop, the IIS/TOR pathway also regulates the production of ILPs in D. melanogaster. Amino acid sensing in the fat body via the TOR pathway controls ILP synthesis and secretion in the IPCs (Britton et al., 2002; Colombani et al., 2003; Geminard et al., 2009). Finally, AMP-activated protein kinase (AMPK) pathway also interacts with the IIS/TOR signaling cascade, although the mechanism of this interaction is not yet clear. AMPK senses energy levels, mostly in the form of AMP levels, and regulates growth in D. melanogaster larvae (Bland et al., 2010; Braco et al., 2012; Mihaylova and Shaw, 2013). As a result of their activity, the IIS/TOR and AMPK pathways determine growth rate of the body and the organs in all animals by regulating ribosome biogenesis, protein translation, autophagy and endocytosis (Grewal, 2009).

Animal body and organ size are not only determined by growth rate but also by the duration of the growth period. In many insects, this process is regulated by a size-dependent developmental checkpoint occurring in the final larval stage called 
critical weight. In D. melanogaster, this developmental milestone coincides with a small peak of the steroid hormone ecdysone and premature ecdysone synthesis causes precocious critical weight achievement (Mirth and Riddiford, 2007). The critical weight checkpoint switches the larva's response to starvation (Nijhout and Williams, 1974; Shingleton et al., 2005; Stieper et al., 2008). Before larvae reach critical weight, starvation significantly delays metamorphosis (Beadle et al., 1938; Nijhout and Williams, 1974). After critical weight, larvae metamorphose early when starved (Mirth et al., 2005; Stieper et al., 2008).

The mechanisms that regulate growth rate and the duration of the growth period are coordinated in insects (Figure 5A). In 2005, Shingleton et al. showed that reducing IIS before critical weight caused developmental delays, whereas reducing IIS after critical weight had no effect on time to metamorphosis (Shingleton et al., 2005). These observations linked IIS to the mechanisms that regulate critical weight for the first time. The observed effects on developmental timing result from IIS in the prothoracic gland (Caldwell et al., 2005; Colombani et al., 2005b; Mirth et al., 2005; Walkiewicz and Stern, 2009). Hyper-activating IIS in this gland produces larvae that reach critical weight prematurely and develop without delay when starved giving rise to smaller adults (Caldwell et al., 2005; Colombani et al., 2005b; Mirth et al., 2005). Altering TOR signaling in the prothoracic gland results in a similar effect on developmental timing (Layalle et al., 2008). Furthermore, upregulating IIS in the prothoracic gland (Caldwell et al., 2005; Colombani et al., 2005b) or upregulating ILP synthesis by the IPCs (Walkiewicz and Stern, 2009) increases the transcription of ecdysone synthesis genes, at least in part through interactions between FoxO and a component of the ecdysone receptor, Ultraspiracle (Koyama et al., 2014). Finally, patterning in the imaginal discs depends on protein consumption before but not after critical weight. Partially activating ecdysone signaling in the wing discs causes premature patterning in pre-critical weight larvae starved of protein (Mirth et al., 2009). Taken together, these observations suggest that growth rate and developmental time are synchronized in the prothoracic gland through the interaction between the IIS/TOR signaling pathway and the ecdysone-producing pathway (Koyama et al., 2013).

Similar to ecdysone, JH both regulates and is regulated by the IIS/TOR signaling pathway. Genetically ablating the corpora allata in D. melanogaster larvae causes them to pupariate at smaller sizes than control larvae (Riddiford et al., 2010). This reduction in body size results from reduced larval growth rate, as loss of $\mathrm{JH}$ does not affect the duration of larval growth period (Mirth et al., 2014). Further, JH affects growth rate via FoxO, which in turn mediates the levels, but not the timing, of ecdysone synthesis in the prothoracic gland (Mirth et al., 2014). Although the mechanism is not yet completely known, ILPs also interact with $\mathrm{JH}$ in $M$. sexta. In this insect, ILPs suppress the $\mathrm{JH}$ repression of pupal commitment that occurs in the absence of nutritional input. It does this by inducing broad expression in wing discs and eye primordia of final instar $M$. sexta larvae (Koyama et al., 2008). Altogether, these results indicate a role for $\mathrm{JH}$ in regulating growth rate via the ecdysone-signaling and IIS/TOR pathways.

\section{SUMMARY}

A variety of environmental conditions impact an animal's development at specific critical times through different processes, but nevertheless common molecular players. This molds growth rates and the duration of growth period, thereby altering body size and the size of individual organs (Figure 5). In some species, this process can result in the generation of eco-morphs, animals that show different morphological traits according to their ecological niche. How is animal behavior coordinated with plasticity in morphological traits?

\section{THE ENVIRONMENT INTERACTS WITH DEVELOPMENTAL PROCESSES TO GENERATE BEHAVIORAL PLASTICITY}

By affecting the production of developmental hormones, nutrition in the larval stages has significant effects on both adult morphology and behavior (Figure 6A). In male dung beetles, nutrition impacts both hormone titres and the IIS/TOR signaling to produce adults that differ in horn length (Figure 6B). Both the dynamics of ecdysone and $\mathrm{JH}$ titres differ at critical times in development between well-fed and poorly-fed males (Emlen and Nijhout, 1999, 2001; Emlen et al., 2005; Rowland and Emlen, 2009; Gilbert, 2011). Furthermore, the IIS/TOR signaling pathway appears to connect horn growth and nutrition (Emlen et al., 2006; Snell-Rood and Moczek, 2012). Finally, after the growth phase, the complete development of horns involves a period of remodeling through apoptosis during the pupal development (Moczek and Nagy, 2005; Moczek, 2006). Although some hypotheses have been advanced (Emlen et al., 2006, 2007; Koyama et al., 2013), the actual mechanisms of how JH and ecdysone act on tissues to regulate horn growth and differentiation are not yet known.

Accompanying the changes in horn morphology, male reproductive strategies in dung beetles depend on the size of their horns (Figure 6B). Males with big horns fight for, mate with, and guard females (Emlen, 1997a). In contrast, shorted-horn males dig "sneaker" tunnels and intercept females as they bury their dung balls (Emlen, 1997a). Potentially, the mechanisms regulating horn length during dung beetle development also affect the structure and activity of the nervous system to define different modes of adult behavior.

Work in D. melanogaster highlights some of the potential mechanisms through which environmental conditions might reprogram behavior. Starving D. melanogaster larvae reduces total body size, and reduces the size, but not the complexity, of $d a$ neurons proportionally (Shimono et al., 2014). However, reducing IIS/TOR signaling in these cells reduces both arbor size and the branch complexity, suggesting that IIS/TOR plays a developmental role during arbor growth, and an environmental role in regulating arbor size. Shimono et al. (2014) found that mutations in a co-chaperone of Hsp90, CHORD, affect arbor scaling without altering branch complexity. Furthermore, CHORD acts downstream of one of two TOR complexes, TORC2, to regulate neuronal scaling. These findings suggest that pathways like IIS/TOR signaling show modularity in their regulation, and that this modularity allows these pathways to affect different developmental processes in response to developmental vs. environmental signals. This type of modularity might be key for shaping 


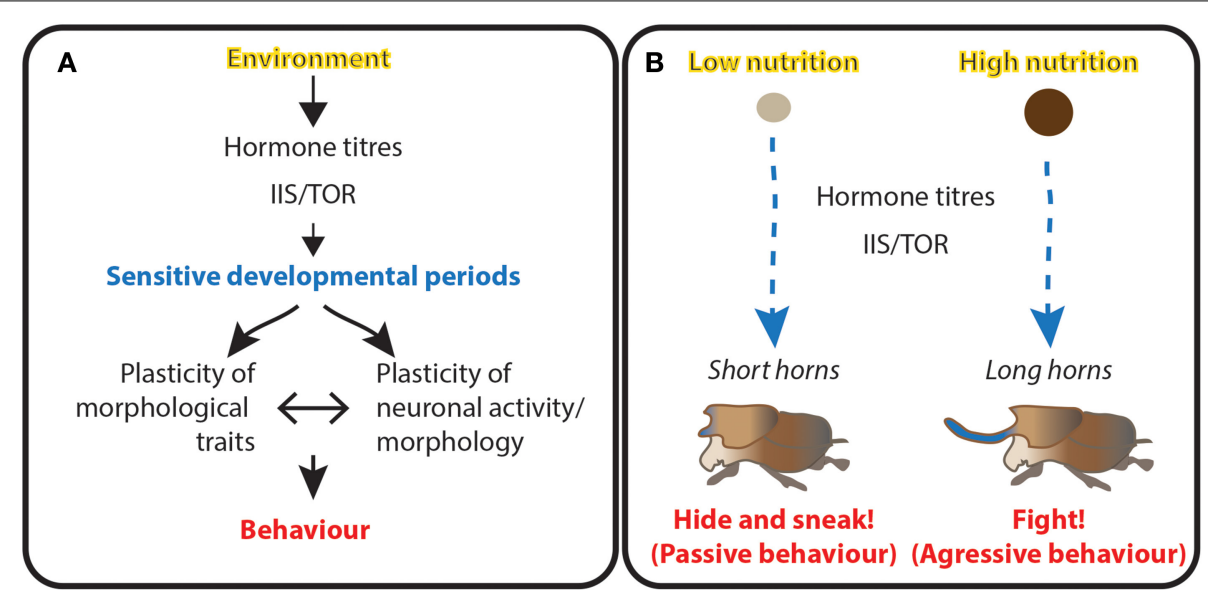

FIGURE 6 | Morphological and behavioral plasticity are coordinated and may be generated through the same developmental

mechanisms. (A) Schematic representation of the interaction between the environment, development and behavior. Environmental conditions (yellow) act on developmental programs by altering hormone titres and the activity of growth pathways at critical sensitive periods of development (blue). The coordination between morphology and connectivity of the neuronal system determines behavior (red) at that particular developmental stage in response to environmental conditions. (B) Example of the triad coordinating adult dung beetle morphology and its mating strategies. We hypothesize the amount of dung available during larval development act through hormone titers and the IIS/TOR (IIS/TOR = insulin/insulin-like growth factor signaling and Target of Rapamycin) pathway to regulate both the size of adult horns and the neuronal circuits underlying mating strategies. This triad ensures animals use the appropriate behavioral repertoire for their morphology. behavioral polyphenisms without disrupting the structure of the neural circuits.

Furthermore, different neuronal classes show varying degrees of plasticity in response to nutrition. In early larval stages, starvation suppresses the proliferation of most neuroblasts (Britton and Edgar, 1998; Chell and Brand, 2010; Cheng et al., 2011; SousaNunes et al., 2011; Lanet et al., 2013). In later stages, proliferation continues even when larvae are starved (Britton and Edgar, 1998; Chell and Brand, 2010; Cheng et al., 2011; Sousa-Nunes et al., 2011; Lanet et al., 2013). In contrast, proliferation in the mushroom body neurons is nutrition-insensitive throughout development (Britton and Edgar, 1998; Lin et al., 2013). Because larvae starved before reaching critical weight show dramatic delays in their onset of metamorphosis, starved, pre-critical weight larvae have many more mushroom body neurons than well-fed larvae (Lin et al., 2013). Mushroom body neurons play important roles in learning and memory, and are proposed to function as parallel processers. The functional significance of increasing the population of mushroom body neurons is unknown, but could potentially represent a mechanism though which environmental conditions during larval development restructure the nervous system to affect adult behaviors.

\section{SUMMARY}

Often, phenotypic plasticity in morphological traits is coordinated with changes in behavior (Figure 6A). Nevertheless, we do not yet know how the development of morphological and behavioral traits is integrated in response to environmental change. Animals have critical periods in their development that are sensitive to environmental variation. During these periods, environmentally dependent-hormone titres are coordinated with growth signaling pathways and with internal sensors that communicate the internal state of the organism to the brain. This interaction molds developmental programs. We speculate that the mechanisms that regulate morphological plasticity also change the neuronal connectivity and/or activity to generate matching differences in behavior in developing animals.

\section{CONCLUSIONS}

Many features of an animal's biology, including body and organ size and shape as well as behavior are not completely hardwired, but result from plastic developmental programs responsive to variation in the environment. Thus, neuronal activity and connectivity are not only reprogrammed by developmental processes, but are also molded by the same environmental conditions that impact organ and body size, and other traits. Variation in the environment impacts both the developmental processes regulating body and organ size that will optimize animal survival in the new environment and the neuronal circuits and neuronal modulators producing behaviors that increase an animal's reproductive success. Possibly, the mechanisms of developmental plasticity of body and trait size are the same that modulate neuronal circuits. This would ensure that animals use the appropriate behavioral repertoire for their morphology (Figure 6A).

For example, what happens in the dung beetle brain that programs long horned males for courtship battles and shorthorned males for sneaking? We hypothesize neuronal connections are restructured at critical sensitive periods by the modulators ecdysone, JH and IIS/TOR, known to shape horn size in response to nutritional quantity (Figure 6B).

The same logic would apply throughout the whole animal development and not necessarily only in adults. We hypothesize stage-specific behaviors are molded by the same developmental mechanisms that generate the morphological traits typical of each developmental stage. 
The understanding of the sensory circuits in different animals will allow us to understand behaviors in their ecologically relevant contexts. To start, the well-established model $D$. melanogaster with its extensive genetic tool kit will allow major advances in this field (Jennings, 2011). In spite of its small brain, the fruit fly shows a wide array of complex behaviors providing a powerful model system to study key features of sensorimotor integration at a mechanistic level. We predict that studies in the fruit fly D. melanogaster will provide important insights into the mechanisms that generate stage-specific behaviors and behavioral plasticity in other animals.

\section{ACKNOWLEDGMENTS}

The Fundação para a Ciência e a Tecnologia (FCT) funded this work in the form of a post doctoral fellowship to Maria João A. Carvalho (SFRH/BPD/75993/2011) and an exploratory grant to Maria João A. Carvalho and Christen K. Mirth (EXPL/BEXBID/0497/2013).

\section{REFERENCES}

Aubin-Horth, N., and Renn, S. C. (2009). Genomic reaction norms: using integrative biology to understand molecular mechanisms of phenotypic plasticity. Mol. Ecol. 18, 3763-3780. doi: 10.1111/j.1365-294X.2009.04313.x

Bader, R., Colomb, J., Pankratz, B., Schrock, A., Stocker, R. F., and Pankratz, M. J. (2007). Genetic dissection of neural circuit anatomy underlying feeding behavior in Drosophila: distinct classes of hugin-expressing neurons. J. Comp. Neurol. 502, 848-856. doi: 10.1002/cne.21342

Beadle, G. W., Tatum, E. L., and Clancy, C. W. (1938). Food level in relation to rate of development and eye pigmentation in Drosophila melanogaster Biol. Bull. 75, 447-462. doi: 10.2307/1537573

Benton, R. (2008). Chemical sensing in Drosophila. Curr. Opin. Neurobiol. 18, 357-363. doi: 10.1016/j.conb.2008.08.012

Bjordal, M., Arquier, N., Kniazeff, J., Pin, J. P., and Leopold, P. (2014). Sensing of amino acids in a dopaminergic circuitry promotes rejection of an incomplete diet in Drosophila. Cell 156, 510-521. doi: 10.1016/j.cell.2013.12.024

Bland, M. L., Lee, R. J., Magallanes, J. M., Foskett, J. K., and Birnbaum, M. J. (2010). AMPK supports growth in Drosophila by regulating muscle activity and nutrient uptake in the gut. Dev. Biol. 344, 293-303. doi: 10.1016/j.ydbio.2010. 05.010

Bodmer, R., and Jan, Y. N. (1987). Morphological differentiation of the embryonic peripheral neurons in Drosophila. Roux's Arch. Dev. Biol. 196, 69-77. doi: 10.1007/BF00402027

Booker, R., and Truman, J. W. (1987). Postembryonic neurogenesis in the CNS of the tobacco hornworm, Manduca sexta. I. Neuroblast arrays and the fate of their progeny during metamorphosis. J. Comp. Neurol. 255, 548-559. doi: $10.1002 / \mathrm{cne} .902550407$

Braco, J. T., Gillespie, E. L., Alberto, G. E., Brenman, J. E., and Johnson, E. C. (2012). Energy-dependent modulation of glucagon-like signaling in Drosophila via the AMP-activated protein kinase. Genetics 192, 457-466. doi: 10.1534/genetics.112.143610

Britton, J. S., and Edgar, B. A. (1998). Environmental control of the cell cycle in Drosophila: nutrition activates mitotic and endoreplicative cells by distinct mechanisms. Development 125, 2149-2158.

Britton, J. S., Lockwood, W. K., Li, L., Cohen, S. M., and Edgar, B. A. (2002). Drosophila's insulin/PI3-kinase pathway coordinates cellular metabolism with nutritional conditions. Dev. Cell 2, 239-249. doi: 10.1016/S15345807(02)00117-X

Broughton, S. J., Piper, M. D., Ikeya, T., Bass, T. M., Jacobson, J., Driege, Y., et al. (2005). Longer lifespan, altered metabolism, and stress resistance in Drosophila from ablation of cells making insulin-like ligands. Proc. Natl. Acad. Sci. U.S.A. 102, 3105-3110. doi: 10.1073/pnas.0405775102

Brown, H. L., and Truman, J. W. (2009). Fine-tuning of secondary arbor development: the effects of the ecdysone receptor on the adult neuronal lineages of the Drosophila thoracic CNS. Development 136, 3247-3256. doi: 10.1242/dev.039859
Brown, H. L., Cherbas, L., Cherbas, P., and Truman, J. W. (2006). Use of timelapse imaging and dominant negative receptors to dissect the steroid receptor control of neuronal remodeling in Drosophila. Development 133, 275-285. doi: 10.1242/dev.02191

Brown, M. R., Crim, J. W., Arata, R. C., Cai, H. N., Chun, C., and Shen, P. (1999). Identification of a Drosophila brain-gut peptide related to the neuropeptide $\mathrm{Y}$ family. Peptides 20, 1035-1042. doi: 10.1016/S0196-9781(99)00097-2

Burgering, B. M. (2008). A brief introduction to FOXOlogy. Oncogene 27, 2258-2262. doi: 10.1038/onc.2008.29

Caldwell, P. E., Walkiewicz, M., and Stern, M. (2005). Ras activity in the Drosophila prothoracic gland regulates body size and developmental rate via ecdysone release. Curr. Biol. 15, 1785-1795. doi: 10.1016/j.cub.2005.09.011

Cassidy, E. J., Bath, E., Chenoweth, S. F., and Bonduriansky, R. (2014). Sexspecific patterns of morphological diversification: evolution of reaction norms and static allometries in neriid flies. Evolution 68, 368-383. doi: 10.1111/evo. 12276

Champlin, D. T., Reiss, S. E., and Truman, J. W. (1999). Hormonal control of ventral diaphragm myogenesis during metamorphosis of the moth, Manduca sexta. Dev. Genes Evol. 209, 265-274. doi: 10.1007/s004270050252

Chell, J. M., and Brand, A. H. (2010). Nutrition-responsive glia control exit of neural stem cells from quiescence. Cell 143, 1161-1173. doi: 10.1016/j.cell.2010.12.007

Cheng, L. Y., Bailey, A. P., Leevers, S. J., Ragan, T. J., Driscoll, P. C., and Gould, A. P. (2011). Anaplastic lymphoma kinase spares organ growth during nutrient restriction in Drosophila. Cell 146, 435-447. doi: 10.1016/j.cell.2011.06.040

Colombani, J., Bianchini, L., Layalle, S., Pondeville, E., Dauphin-Villemant, C., Antoniewski, C., et al. (2005a). Antagonistic actions of ecdysone and insulins determine final size in Drosophila. Science 310, 667-670. doi: 10.1126/science. 1119432

Colombani, J., Bianchini, L., Layalle, S., Pondeville, E., Dauphin-Villemant, C., Antoniewski, C., et al. (2005b). Antagonistic actions of ecdysone and insulins determine final size in Drosophila. Science 310, 667-670. doi: 10.1126/science. 1119432

Colombani, J., Raisin, S., Pantalacci, S., Radimerski, T., Montagne, J., and Leopold, P. (2003). A nutrient sensor mechanism controls Drosophila growth. Cell 114, 739-749. doi: 10.1016/S0092-8674(03)00713-X

Cordes, N., Albrecht, F., Engqvist, L., Schmoll, T., Baier, M., Muller, C., et al. (2014). Larval food composition affects courtship song and sperm expenditure in a lekking moth. Ecol. Entomol. 39, 34-41. doi: 10.1111/een.12156

De Virgilio, C., and Loewith, R. (2006). The TOR signalling network from yeast to man. Int. J. Biochem. Cell Biol. 38, 1476-1481. doi: 10.1016/j.biocel.2006.02.013

Desor, J. A., Maller, O., and Turner, R. E. (1977). Preference for Sweet in Humans: Infants, Children and Adults. Washington, DC: US Government Printing Office.

Dhaka, A., Viswanath, V., and Patapoutian, A. (2006). Trp ion channels and temperature sensation. Annu. Rev. Neurosci. 29, 135-161. doi: 10.1146/annurev.neuro.29.051605.112958

Emlen, D. J. (1994). Environmental control of horn lenght dimorphism in the beetle Onthophagus acuminatus (Coleoptera: Scarabaeidae). Proc. R. Soc. Lond. B Biol. Sci. 256, 131-136. doi: 10.1098/rspb.1994.0060

Emlen, D. J. (1997a). Alternative reproductive tactics and male dimorphism in the horned beetle Onthophagus acuminatus (Coleoptera: Scarabaeidae). Behav. Ecol. Sociol. 41, 335-341. doi: 10.1007/s002650050393

Emlen, D. J. (1997b). Diet alters male horn allometry in the beetle Onthophagus acuminatus (Coleoptera: Scarabaeidae). Proc. R. Soc. Lond. B Biol. Sci. 264, 567-574. doi: 10.1098/rspb.1997.0081

Emlen, D. J., and Nijhout, H. F. (1999). Hormonal control of male horn length dimorphism in the dung beetle Onthophagus taurus (Coleoptera: Scarabaeidae). J. Insect Physiol. 45, 45-53. doi: 10.1016/S0022-1910(98)00096-1

Emlen, D. J., and Nijhout, H. F. (2001). Hormonal control of male horn length dimorphism in Onthophagus taurus (Coleoptera: Scarabaeidae): a second critical period of sensitivity to juvenile hormone. J. Insect Physiol. 47, 1045-1054. doi: 10.1016/S0022-1910(01)00084-1

Emlen, D. J., Corley Lavine, L., and Ewen-Campen, B. (2007). On the origin and evolutionary diversification of beetle horns. Proc. Natl. Acad. Sci. U.S.A. 104(Suppl. 1), 8661-8668. doi: 10.1073/pnas.0701209104

Emlen, D. J., Hunt, J., and Simmons, L. W. (2005). Evolution of sexual dimorphism and male dimorphism in the expression of beetle horns: phylogenetic evidence for modularity, evolutionary lability, and constraint. Am. Nat. 166(Suppl. 4), S42-S68. doi: 10.1086/444599 
Emlen, D. J., Szafran, Q., Corley, L. S., and Dworkin, I. (2006). Insulin signaling and limb-patterning: candidate pathways for the origin and evolutionary diversification of beetle 'horns.' Heredity 97, 179-191. doi: 10.1038/sj.hdy.6800868

Geminard, C., Rulifson, E. J., and Leopold, P. (2009). Remote control of insulin secretion by fat cells in Drosophila. Cell Metab. 10, 199-207. doi 10.1016/j.cmet.2009.08.002

Gerber, B., and Stocker, R. F. (2007). The Drosophila larva as a model for studying chemosensation and chemosensory learning: a review. Chem. Senses 32, 65-89. doi: $10.1093 /$ chemse/bjl030

Gerber, B., Stocker, R. F., Tanimura, T., and Thum, A. S. (2009). "Smelling, tasting, learning: Drosophila as a study case," in Chemosensory Systems in Mammals, Fishes, and Insects, eds S. Korsching and W. Meyerhof (Berlin; Heidelberg: Springer), 187-202.

Gilbert, L. (2011). Insect Endocrinology. London; Waltham; San Diego: Academic Press.

Gilbert, L. I., Rybczynski, R., and Warren, J. T. (2002). Control and biochemical nature of the ecdysteroidogenic pathway. Annu. Rev. Entomol. 47, 883-916. doi: 10.1146/annurev.ento.47.091201.145302

Golub, J. L., and Brown, G. E. (2003). Are all signals the same? Ontogenetic change in the response to conspecific and heterospecific chemical alarm signals by juvenile green sunfish (Lepomis cyanellus). Behav. Ecol. Sociobiol. 54, 113-118. doi: 10.1007/s00265-003-0629-9

Gong, Z., Liu, J., Guo, C., Zhou, Y., Teng, Y., and Liu, L. (2010). Two pairs of neurons in the central brain control Drosophila innate light preference. Science 330, 499-502. doi: 10.1126/science. 1195993

Grewal, S. S. (2009). Insulin/TOR signaling in growth and homeostasis: a view from the fly world. Int. J. Biochem. Cell Biol. 41, 1006-1010. doi: 10.1016/j.biocel.2008.10.010

Grossfield, J. (1978). "Non-sexual behavior of Drosophila," in The Genetics and Biology of Drosophila, eds M. Ashburner and T. R. F. Wright (London: Academic Press), 1-126.

Grueber, W. B., Jan, L. Y., and Jan, Y. N. (2002). Tiling of the Drosophila epidermis by multidendritic sensory neurons. Development 129, 2867-2878.

Grueber, W. B., Ye, B., Yang, C. H., Younger, S., Borden, K., Jan, L. Y., et al. (2007). Projections of Drosophila multidendritic neurons in the central nervous system: links with peripheral dendrite morphology. Development $134,55-64$. doi: 10.1242/dev.02666

Gu, S. H., Lin, J. L., Lin, P. L., and Chen, C. H. (2009). Insulin stimulates ecdysteroidogenesis by prothoracic glands in the silkworm, Bombyx mori. Insect Biochem. Mol. Biol. 39, 171-179. doi: 10.1016/j.ibmb.2008.10.012

Hamada, F. N., Rosenzweig, M., Kang, K., Pulver, S. R., Ghezzi, A., Jegla, T. J., et al. (2008). An internal thermal sensor controlling temperature preference in Drosophila. Nature 454, 217-220. doi: 10.1038/nature07001

Hufnagel, A. (1918). Recherches histologiques sur le metamorphose d'un lepidoptere Hyponomeuta padella L. Arch. Zool. Exp. Genet. 57, 47-202.

Huston, S. J., and Jayaaman, V. (2011). Studying sensorimotor integration in insects. Curr. Opin. Neurobiol. 21, 527-534. doi: 10.1016/j.conb.2011.05.030

Hwang, R. Y., Zhong, L., Xu, Y., Johnson, T., Zhang, F., Deisseroth, K., et al. (2007). Nociceptive neurons protect Drosophila larvae from parasitoid wasps. Curr. Biol. 17, 2105-2116. doi: 10.1016/j.cub.2007.11.029

Im, S. H., and Galko, M. J. (2012). Pokes, sunburn, and hot sauce: Drosophila as an emerging model for the biology of nociception. Dev. Dyn. 241, 16-26. doi: 10.1002/dvdy.22737

Jaramillo, S. L., Mehlferber, E., and Moore, P. J. (2014). Life-history trade-offs under different larval diets in Drosophila suzukii (Diptera: Drosophilidae). Physiol. Entomol. doi: 10.1111/phen.12082. [Epub ahead of print].

Jennings, B. H. (2011). Drosophila - a versatile model in biology and medicine. Materialstoday 14, 190-195. doi: 10.1016/S1369-7021(11)70113-4

Johnson, M. H. (2001). Functional brain development in humans. Nat. Rev. Neurosci. 2, 475-483. doi: 10.1038/35081509

Junger, M. A., Rintelen, F., Stocker, H., Wasserman, J. D., Vegh, M., Radimerski, T. et al. (2003). The Drosophila forkhead transcription factor FOXO mediates the reduction in cell number associated with reduced insulin signaling. J. Biol. 2:20. doi: 10.1186/1475-4924-2-20

Kane, E. A., Gershow, M., Afonso, B., Larderet, I., Klein, M., Carter, A. R., et al. (2013). Sensorimotor structure of Drosophila larva phototaxis. Proc. Natl. Acad. Sci. U.S.A. 110, E3868-E3877. doi: 10.1073/pnas.1215295110

Kaneko, M., Helfrich-Forster, C., and Hall, J. C. (1997). Spatial and temporal expression of the period and timeless genes in the developing nervous system of
Drosophila: newly identified pacemaker candidates and novel features of clock gene product cycling. J. Neurosci. Off. J. Soc. Neurosci. 17, 6745-6760.

Kang, K., Panzano, V. C., Chang, E. C., Ni, L., Dainis, A. M., Jenkins, A. M., et al. (2012). Modulation of TRPA1 thermal sensitivity enables sensory discrimination in Drosophila. Nature 481, 76-80. doi: 10.1038/nature10715

Kang, K., Pulver, S. R., Panzano, V. C., Chang, E. C., Griffith, L. C., Theobald, D. L., et al. (2010). Analysis of Drosophila TRPAl reveals an ancient origin for human chemical nociception. Nature 464, 597-600. doi: 10.1038/nature 08848

Keene, A. C., and Sprecher, S. G. (2012). Seeing the light: photobehavior in fruit fly larvae. Trends Neurosci. 35, 104-110. doi: 10.1016/j.tins.2011.11.003

Koyama, T., Mendes, C. C., and Mirth, C. K. (2013). Mechanisms regulating nutrition-dependent developmental plasticity through organ-specific effects in insects. Front. Physiol. 4:263. doi: 10.3389/fphys.2013.00263

Koyama, T., Rodrigues, M. A., Athanasiadis, A., Shingleton, A. W., and Mirth, C. K. (2014). Nutritional control of body size through FoxO-Ultraspiracle mediated ecdysone biosynthesis. Elife 3:e03091. doi: 10.7554/eLife.03091

Koyama, T., Syropyatova, M. O., and Riddiford, L. M. (2008). Insulin/IGF signaling regulates the change in commitment in imaginal discs and primordia by overriding the effect of juvenile hormone. Dev. Biol. 324, 258-265. doi: 10.1016/j.ydbio.2008.09.017

Lanet, E., Gould, A. P., and Maurange, C. (2013). Protection of neuronal diversity at the expense of neuronal numbers during nutrient restriction in the Drosophila visual system. Cell Rep. 3, 587-594. doi: 10.1016/j.celrep.2013.02.006

Layalle, S., Arquier, N., and Leopold, P. (2008). The TOR pathway couples nutrition and developmental timing in Drosophila. Dev. Cell 15, 568-577. doi: 10.1016/j.devcel.2008.08.003

Lee, K. P., Simpson, S. J., Clissold, F. J., Brooks, R., Ballard, J. W., Taylor, P. W., et al. (2008a). Lifespan and reproduction in Drosophila: new insights from nutritional geometry. Proc. Natl. Acad. Sci. U.S.A. 105, 2498-2503. doi: 10.1073/pnas.0710787105

Lee, K. S., Hong, S. H., Kim, A. K., Ju, S. K., Kwon, O. Y., and Yu, K. (2009). Processed short neuropeptide $\mathrm{F}$ peptides regulate growth through the ERKinsulin pathway in Drosophila melanogaster. FEBS Lett. 583, 2573-2577. doi: 10.1016/j.febslet.2009.07.024

Lee, K. S., Kwon, O. Y., Lee, J. H., Kwon, K., Min, K. J., Jung, S. A., et al. (2008b) Drosophila short neuropeptide $\mathrm{F}$ signalling regulates growth by ERK-mediated insulin signalling. Nat. Cell Biol. 10, 468-475. doi: 10.1038/ncb1710

Lee, K. S., You, K. H., Choo, J. K., Han, Y. M., and Yu, K. (2004). Drosophila short neuropeptide F regulates food intake and body size. J. Biol. Chem. 279, 50781-50789. doi: 10.1074/jbc.M407842200

Levine, R. B., and Truman, J. W. (1982). Metamorphosis of the insect nervous system: changes in morphology and synaptic interactions of identified neurones Nature 299, 250-252. doi: 10.1038/299250a0

Levine, R. B., and Truman, J. W. (1985). Dendritic reorganization of abdominal motoneurons during metamorphosis of the moth, Manduca sexta. J. Neurosci. 5, 2424-2431.

Levine, R. D. (1984). Changes in neuronal circuits during insect metamorphosis. J. Exp. Biol. 112, 27-44.

Lin, S., Marin, E. C., Yang, C. P., Kao, C. F., Apenteng, B. A., Huang, Y., et al. (2013). Extremes of lineage plasticity in the Drosophila brain. Curr. Biol. 23, 1908-1913. doi: 10.1016/j.cub.2013.07.074

Lingo, P. R., Zhao, Z., and Shen, P. (2007). Co-regulation of coldresistant food acquisition by insulin- and neuropeptide Y-like systems in Drosophila melanogaster. Neuroscience 148, 371-374. doi: 10.1016/j.neuroscience.2007.06.010

Liu, L., Yermolaieva, O., Johnson, W. A., Abboud, F. M., and Welsh, M. J. (2003). Identification and function of thermosensory neurons in Drosophila larvae. Nat. Neurosci. 6, 267-273. doi: 10.1038/nn1009

Malpel, S., Klarsfeld, A., and Rouyer, F. (2002). Larval optic nerve and adult extra-retinal photoreceptors sequentially associate with clock neurons during Drosophila brain development. Development 129, 1443-1453.

Mazzoni, E. O., Desplan, C., and Blau, J. (2005). Circadian pacemaker neurons transmit and modulate visual information to control a rapid behavioral response. Neuron 45, 293-300. doi: 10.1016/j.neuron.2004.12.038

McBrayer, Z., Ono, H., Shimell, M., Parvy, J. P., Beckstead, R. B., Warren, J. T., et al. (2007). Prothoracicotropic hormone regulates developmental timing and body size in Drosophila. Dev. Cell 13, 857-871. doi: 10.1016/j.devcel.2007. 11.003 
Melcher, C., and Pankratz, M. J. (2005). Candidate gustatory interneurons modulating feeding behavior in the Drosophila brain. PLoS Biol. 3:e305. doi: 10.1371/journal.pbio.0030305

Melcher, C., Bader, R., and Pankratz, M. J. (2007). Amino acids, taste circuits, and feeding behavior in Drosophila: towards understanding the psychology of feeding in flies and man. J. Endocrinol. 192, 467-472. doi: 10.1677/JOE06-0066

Mennella, J. A., Pepino, M. Y., and Beauchamp, G. K. (2003). Modification of bitter taste in children. Dev. Psychobiol. 43, 120-127. doi: 10.1002/dev.10127

Mennella, J. A., Pepino, M. Y., and Reed, D. R. (2005). Genetic and environmental determinants of bitter perception and sweet preferences. Pediatrics 115, e216-e222. doi: 10.1542/peds.2004-1582

Menzel, R., and Muller, U. (1996). Learning and memory in honeybees: from behavior to neural substrates. Annu. Rev. Neurosci. 19, 379-404. doi: 10.1146/annurev.ne.19.030196.002115

Mihaylova, M. M., and Shaw, R. J. (2013). Metabolic reprogramming by class I and II histone deacetylases. Trends Endocrinol. Metab. 24, 48-57. doi: 10.1016/j.tem.2012.09.003

Mirth, C. K., and Riddiford, L. M. (2007). Size assessment and growth control: how adult size is determined in insects. Bioessays 29, 344-355. doi 10.1002/bies.20552

Mirth, C. K., and Shingleton, A. W. (2012). Integrating body and organ size in Drosophila: recent advances and outstanding problems. Front. Endocrinol. (Lausanne) 3:49. doi: 10.3389/fendo.2012.00049

Mirth, C. K., Tang, H. Y., Makohon-Moore, S. C., Salhadar, S., Gokhale, R. H., Warner, R. D., et al. (2014). Juvenile hormone regulates body size and perturbs insulin signaling in Drosophila. Proc. Natl. Acad. Sci. U.S.A. 111, 7018-7023. doi: $10.1073 /$ pnas. 1313058111

Mirth, C. K., Truman, J. W., and Riddiford, L. M. (2009). The ecdysone receptor controls the post-critical weight switch to nutrition-independent differentiation in Drosophila wing imaginal discs. Development 136, 2345-2353. doi: 10.1242/dev.032672

Mirth, C., Truman, J. W., and Riddiford, L. M. (2005). The role of the prothoracic gland in determining critical weight for metamorphosis in Drosophila melanogaster. Curr. Biol. 15, 1796-1807. doi: 10.1016/j.cub.2005.09.017

Miyamoto, T., Slone, J., Song, X., and Amrein, H. (2012). A fructose receptor functions as a nutrient sensor in the Drosophila brain. Cell 151, 1113-1125. doi: 10.1016/j.cell.2012.10.024

Moczek, A. P. (2006). Pupal remodeling and the development and evolution of sexual dimorphism in horned beetles. Am. Nat. 168, 711-729. doi: 10.1086/ 509051

Moczek, A. P., and Nagy, L. M. (2005). Diverse developmental mechanisms contribute to different levels of diversity in horned beetles. Evol. Dev. 7, 175-185 doi: 10.1111/j.1525-142X.2005.05020.x

Nassel, D. R. (2002). Neuropeptides in the nervous system of Drosophila and other insects: multiple roles as neuromodulators and neurohormones. Prog. Neurobiol. 68, 1-84. doi: 10.1016/S0301-0082(02)00057-6

Nassel, D. R., and Wegener, C. (2011). A comparative review of short and long neuropeptide F signaling in invertebrates: any similarities to vertebrate neuropeptide Y signaling? Peptides 32, 1335-1355. doi: 10.1016/j.peptides.2011.03.013

Nassel, D. R., and Winther, A. M. (2010). Drosophila neuropeptides in regulation of physiology and behavior. Prog. Neurobiol. 92, 42-104. doi: 10.1016/j.pneurobio.2010.04.010

Nijhout, H. F., and Williams, C. M. (1974). Control of molting and metamorphosis in the tobacco hornworm, Manduca sexta (L.): growth of the last-instar larva and the decision to pupate. J. Exp. Biol. 61, 481-491.

Ohyama, T., Jovanic, T., Denisov, G., Dang, T. C., Hoffmann, D., Kerr, R. A., et al. (2013). High-throughput analysis of stimulus-evoked behaviors in Drosophila larva reveals multiple modality-specific escape strategies. PLoS ONE 8:e71706. doi: 10.1371/journal.pone.0071706

Oldham, S., and Hafen, E. (2003). Insulin/IGF and target of rapamycin signaling: a TOR de force in growth control. Trends Cell Biol. 13, 79-85. doi: 10.1016/S09628924(02)00042-9

Perez, C. (1910). Recherches histologiques sur la metamorphose des muscides (Calliphora erythrocephala). Arch. Zool. Exp. Genet. 4:274.

Pool, A. H., and Scott, K. (2014). Feeding regulation in Drosophila. Curr. Opin. Neurobiol. 29C, 57-63. doi: 10.1016/j.conb.2014.05.008

Prokop, A., and Technau, G. M. (1991). The origin of postembryonic neuroblasts in the ventral nerve cord of Drosophila melanogaster. Development 111, 79-88.
Raubenheimer, D., and Simpson, S. J. (1997). Integrative models of nutrient balancing: application to insects and vertebrates. Nutr. Res. Rev. 10, 151-179. doi: 10.1079/NRR19970009

Renn, S. C., Park, J. H., Rosbash, M., Hall, J. C., and Taghert, P. H. (1999). A pdf neuropeptide gene mutation and ablation of PDF neurons each cause severe abnormalities of behavioral circadian rhythms in Drosophila. Cell 99, 791-802. doi: 10.1016/S0092-8674(00)81676-1

Rewitz, K. F., Yamanaka, N., Gilbert, L. I., and O'Connor, M. B. (2009). The insect neuropeptide PTTH activates receptor tyrosine kinase torso to initiate metamorphosis. Science 326, 1403-1405. doi: 10.1126/science.1176450

Riddiford, L. M. (1996). Juvenile hormone: the status of its "status quo" action. Arch. Insect Biochem. Physiol. 32, 271-286.

Riddiford, L. M., Truman, J. W., Mirth, C. K., and Shen, Y. C. (2010). A role for juvenile hormone in the prepupal development of Drosophila melanogaster. Development 137, 1117-1126. doi: 10.1242/dev.037218

Robertson, J. L., Tsubouchi, A., and Tracey, W. D. (2013). Larval defense against attack from parasitoid wasps requires nociceptive neurons. PLoS ONE 8:e78704. doi: 10.1371/journal.pone.0078704

Robinson, G. E. (2002). Genomics and integrative analyses of division of labor in honeybee colonies. Am. Nat. 160(Suppl. 6), S160-S172. doi: 10.1086/ 342901

Roman, G., and Davis, R. L. (2001). Molecular biology and anatomy of Drosophila olfactory associative learning. Bioessays 23, 571-581. doi: 10.1002/bies.1083

Root, C. M., Ko, K. I., Jafari, A., and Wang, J. W. (2011). Presynaptic facilitation by neuropeptide signaling mediates odor-driven food search. Cell 145, 133-144. doi: 10.1016/j.cell.2011.02.008

Rosenzweig, M., Brennan, K. M., Tayler, T. D., Phelps, P. O., Patapoutian, A., and Garrity, P. A. (2005). The Drosophila ortholog of vertebrate TRPA1 regulates thermotaxis. Genes Dev. 19, 419-424. doi: 10.1101/gad.1278205

Rowland, J. M., and Emlen, D. J. (2009). Two thresholds, three male forms result in facultative male trimorphism in beetles. Science 323, 773-776. doi: 10.1126/science. 1167345

Rulifson, E. J., Kim, S. K., and Nusse, R. (2002). Ablation of insulin-producing neurons in flies: growth and diabetic phenotypes. Science 296, 1118-1120. doi: $10.1126 /$ science. 1070058

Sawin, E. P., Harris, L. R., Campos, A. R., and Sokoiowski, M. B. (1994). Sensorimotor transformation from light reception to phototactic behavior in Drosophila larvae (Diptera: Drosophilidae). J. Insect Behav. 7, 553-567. doi: 10.1007/BF02025449

Sawin-McCormack, E. P., Sokolowski, M. B., and Campos, A. R. (1995). Characterization and genetic analysis of Drosophila melanogaster photobehavior during larval development. J. Neurogenet. 10, 119-135. doi: $10.3109 / 01677069509083459$

Scott, K. (2005). Taste recognition: food for thought. Neuron 48, 455-464. doi: 10.1016/j.neuron.2005.10.015

Sentinella, A. T., Crean, A. J., and Bonduriansky, R. (2013). Dietary protein mediates a trade-off between larval survival and the development of male secondary sexual traits. Funct. Ecol. 27, 1134-1144. doi: 10.1111/1365-2435.12104

Shepherd, D., and Smith, S. A. (1996). Central projections of persistent larval sensory neurons prefigure adult sensory pathways in the CNS of Drosophila. Development 122, 2375-2384.

Shimono, K., Fujishima, K., Nomura, T., Ohashi, M., Usui, T., Kengaku, M., et al. (2014). An evolutionarily conserved protein CHORD regulates scaling of dendritic arbors with body size. Sci. Rep. 4, 1-8. doi: 10.1038/srep04415

Shingleton, A. W., Das, J., Vinicius, L., and Stern, D. L. (2005). The temporal requirements for insulin signaling during development in Drosophila. PLoS Biol. 3:e289. doi: 10.1371/journal.pbio.0030289

Simpson, S. J., and Simpson, C. L. (1992). Mechanisms controlling modulation by haemolymph amino acids of gustatory responsiveness in the Locust. J. Exp. Biol. $168,269-287$.

Simpson, S. J., Batley, R., and Raubenheimer, D. (2003). Geometric analysis of macronutrient intake in humans: the power of protein? Appetite 41, 123-140. doi: 10.1016/S0195-6663(03)00049-7

Snell-Rood, E. C., and Moczek, A. P. (2012). Insulin signaling as a mechanism underlying developmental plasticity: the role of FOXO in a nutritional polyphenism. PLoS ONE 7:e34857. doi: 10.1371/journal.pone.0034857

Sokolowski, M. B., Kent, C., and Wong, J. (1984). Drosophila larval foraging behaviour: developmental stages. Anim. Behav. 32, 645-651. doi: 10.1016/S0003-3472(84)80139-6 
Sousa-Nunes, R., Yee, L. L., and Gould, A. P. (2011). Fat cells reactivate quiescent neuroblasts via TOR and glial insulin relays in Drosophila. Nature 471, 508-512. doi: 10.1038/nature09867

Stieper, B. C., Kupershtok, M., Driscoll, M. V., and Shingleton, A. W. (2008). Imaginal discs regulate developmental timing in Drosophila melanogaster. Dev. Biol. 321, 18-26. doi: 10.1016/j.ydbio.2008.05.556

Technau, G., and Heisenberg, M. (1982). Neural reorganization during metamorphosis of the corpora pedunculata in Drosophila melanogaster. Nature 295, 405-407. doi: 10.1038/295405a0

Tracey, W. D. Jr., Wilson, R. I., Laurent, G., and Benzer, S. (2003). painless, a Drosophila gene essential for nociception. Cell 113, 261-273. doi: 10.1016/S0092-8674(03)00272-1

Truman, J. W. (1990). Metamorphosis of the central nervous system of Drosophila. J. Neurobiol. 21, 1072-1084. doi: 10.1002/neu.480210711

Truman, J. W., and Bate, M. (1988). Spatial and temporal patterns of neurogenesis in the central nervous system of Drosophila melanogaster. Dev. Biol. 125, 145-157. doi: 10.1016/0012-1606(88)90067-X

Truman, J. W., and Riddiford, L. M. (1974). Physiology of insect rhythms. 3. The temporal organization of the endocrine events underlying pupation of the tobacco hornworm. J. Exp. Biol. 60, 371-382.

Truman, J. W., Schuppe, H., Shepherd, D., and Williams, D. W. (2004). Developmental architecture of adult-specific lineages in the ventral CNS of Drosophila. Development 131, 5167-5184. doi: 10.1242/dev.01371

Truman, J. W., Talbot, W. S., Fahrbach, S. E., and Hogness, D. S. (1994). Ecdysone receptor expression in the CNS correlates with stage-specific responses to ecdysteroids during Drosophila and Manduca development. Development 120, 219-234.

Vosshall, L. B., and Stocker, R. F. (2007). Molecular architecture of smell and taste in Drosophila. Annu. Rev. Neurosci. 30, 505-533. doi: 10.1146/annurev.neuro.30.051606.094306

Walkiewicz, M. A., and Stern, M. (2009). Increased insulin/insulin growth factor signaling advances the onset of metamorphosis in Drosophila. PLoS ONE 4:e5072. doi: 10.1371/journal.pone.0005072

Walsh, A. L., and Smith, W. A. (2011). Nutritional sensitivity of fifth instar prothoracic glands in the tobacco hornworm, Manduca sexta. J. Insect Physiol. 57, 809-818. doi: 10.1016/j.jinsphys.2011.03.009

Weeks, J. C., and Truman, J. W. (1985). Independent steroid control of the fates of motoneurons and their muscles during insect metamorphosis. J. Neurosci. 5 , 2290-2300.

West-Eberhard, M. J. (2003). Developmental Plasticity and Evolution. New York, NY: Oxford University Press.

Whitman, D. W. and Ananthakrishnan, T. N. (eds.). (2009). Phenotypic Plasticity of Insects: Mechanism and Consequences. Enfield, NH: Science Publishers.

Williams, C. M. (1961). Juvenile hormone II. Its role in endocrine control of molting, pupation, and adult development in cecropia silkworm. Biol. Bull. 121, 572-585. doi: $10.2307 / 1539456$
Williams, D. W., and Shepherd, D. (1999). Persistent larval sensory neurons in adult Drosophila melanogaster. J. Neurobiol. 39, 275-286.

Williams, D. W., and Truman, J. W. (2004). Mechanisms of dendritic elaboration of sensory neurons in Drosophila: insights from in vivo time lapse. J. Neurosci. Off. J. Soc. Neurosci. 24, 1541-1550. doi: 10.1523/JNEUROSCI.452103.2004

Williams, D. W., and Truman, J. W. (2005). Cellular mechanisms of dendrite pruning in Drosophila: insights from in vivo time-lapse of remodeling dendritic arborizing sensory neurons. Development 132, 3631-3642. doi: 10.1242/dev.01928

Winston, M. L. (1991). The Biology of the Honey Bee. Cambridge, MA: Harvard Univerty Press.

Wu, Q., Zhang, Y., Xu, J., and Shen, P. (2005a). Regulation of hunger-driven behaviors by neural ribosomal S6 kinase in Drosophila. Proc. Natl. Acad. Sci. USA. 102, 13289-13294. doi: 10.1073/pnas.0501914102

Wu, Q., Zhao, Z., and Shen, P. (2005b). Regulation of aversion to noxious food by Drosophila neuropeptide Y- and insulin-like systems. Nat. Neurosci. 8, 1350-1355. doi: 10.1038/nn1540

Xiang, Y., Yuan, Q., Vogt, N., Looger, L. L., Jan, L. Y., and Jan, Y. N. (2010). Light-avoidance-mediating photoreceptors tile the Drosophila larval body wall. Nature 468, 921-926. doi: 10.1038/nature09576

Yamanaka, N., Romero, N. M., Martin, F. A., Rewitz, K. F., Sun, M., O'Connor, M. B., et al. (2013). Neuroendocrine control of Drosophila larval light preference. Science 341, 1113-1116. doi: 10.1126/science. 1241210

Zhong, L., Hwang, R. Y., and Tracey, W. D. (2010). Pickpocket is a DEG/ENaC protein required for mechanical nociception in Drosophila larvae. Curr. Biol. 20, 429-434. doi: 10.1016/j.cub.2009.12.057

Conflict of Interest Statement: The authors declare that the research was conducted in the absence of any commercial or financial relationships that could be construed as a potential conflict of interest.

Received: 24 October 2014; accepted: 13 January 2015; published online: 03 February 2015.

Citation: Carvalho MJA and Mirth CK (2015) Coordinating morphology with behavior during development: an integrative approach from a fly perspective. Front. Ecol. Evol. 3:5. doi: 10.3389/fevo.2015.00005

This article was submitted to Behavioral and Evolutionary Ecology, a section of the journal Frontiers in Ecology and Evolution.

Copyright (c) 2015 Carvalho and Mirth. This is an open-access article distributed under the terms of the Creative Commons Attribution License (CC BY). The use, distribution or reproduction in other forums is permitted, provided the original author(s) or licensor are credited and that the original publication in this journal is cited, in accordance with accepted academic practice. No use, distribution or reproduction is permitted which does not comply with these terms. 